\section{Electron Microprobe Analysis of the Metallic Phase in Basic Achondrites}

There are no modern analyses in the literature of the nickel and cobalt contents of the rare metallic phase in those achondritic meteorites which have gross chemical compositions similar to terrestrial basic igneous rocks. I have called these achondrites the basic achondrites and both the eucrites and the howardites are included in this group.

The question of the composition of the metallic grains in basic achondrites has an important bearing on the evolution of these meteorites but the main problem is that their rarity and small sizes have made accurate conventional chemical analysis difficult. In the work recorded here an Applied Research Laboratories electron probe X-ray microanalyser was used to determine iron, nickel and cobalt abundances in a number of metallic grains in the Macibini eucrite and the Binda howardite. The analytical method and the standards used have been described previously ${ }^{1}$.

Table 1. ANalyses of Metallic Grains in Basic Achondrites

$\begin{array}{cccccc}\text { Meteorite } & \begin{array}{c}\text { Metallic grain } \\ \text { identiflcation }\end{array} & \begin{array}{c}\mathrm{Fe} \\ (\%)\end{array} & \begin{array}{c}\text { Ni } \\ (\%)\end{array} & \begin{array}{c}\text { Co } \\ (\%)\end{array} & \text { Ni/Co } \\ \text { Macibini eucrite } & 1 & 97 \cdot 3 & 2 \cdot 15 & 0 \cdot 54 & 4 \cdot 0 \\ & 2 & 93 \cdot 2 & 2 \cdot 21 & 0 \cdot 54 & 4 \cdot 1 \\ & 3 & 97 \cdot 3 & 2 \cdot 00 & 0 \cdot 64 & \mathbf{3} \cdot 1 \\ & 4 & 97 \cdot 2 & 2 \cdot 53 & 0 \cdot 29 & 8 \cdot 7 \\ \text { Binda howardite } & 5 & 95 \cdot 2 & 3 \cdot 85 & 0 \cdot 92 & 4 \cdot 2 \\ & 1 & 95 \cdot 8 & 1 \cdot 95 & 2 \cdot 19 & 0 \cdot 89 \\ & 2 & 98 \cdot 2 & 0 \cdot 44 & 1 \cdot 38 & 0 \cdot 32 \\ & 3 & 95 \cdot 9 & 1 \cdot 93 & 2 \cdot 20 & 0 \cdot 88 \\ & 4 & 95 \cdot 8 & 2 \cdot 00 & 2 \cdot 18 & 0 \cdot 92 \\ & 5 & 95 \cdot 7 & 2 \cdot 10 & 2 \cdot 19 & 0 \cdot 96 \\ & 6 & 95 \cdot 7 & 2 \cdot 06 & 2 \cdot 22 & 0.93\end{array}$

The results indicate that although the nickel and cobalt coritents measured at various places on individual grains seem to be constant within the precision of the method (approximately \pm 3 per cent), there is considerable variability between different grains in each meteorite. In the Macibini eucrite the nickel content of various metallic grains ranged from 2.00 to 3.85 per cent and cobalt ranged from 0.29 per cent to 0.92 per cent (nickel/cobalt $=4 \cdot 0$ 8.7). In the metallio grains in the Binda howardite, nickel ranged from $0 \cdot 44$ to $2 \cdot 1$ per cent and cobalt from 1.38 to $2 \cdot 22$ per cent (nickel/cobalt $=0.32-0.96$ ) (Table 1). Both these meteorites show evidence of severe brecciation so that the variation observed between grains within each achondrite may well result from slight differences in the environments in which individual metallic grains were formed.

The low nickel/cobalt ratios measured in the metallic grains of the basic achondrites are quite different from the ratios observed in the metallic phase of other meteorites. For example, the average nickel/cobalt ratio in the metallic phase of the hypersthene-olivine, bronzite-olivine and enstatite chondrites is close to 20 . Similarly the average nickel/cobalt ratio in the metallic phase of pallasites, which has previously been suggested to be the parent material from which the iron meteorites have evolved ${ }^{2}$, is also 20 (Table 2).

Table 2. Composition of Meramlyc Phase in Meteoritic and Terrestrial MATERIALS

$\begin{array}{lcccc}\text { Material } & \begin{array}{c}\mathrm{Fe} \\ (\%)\end{array} & \begin{array}{c}\mathrm{Ni} \\ (\%)\end{array} & \begin{array}{c}\mathrm{Co} \\ (\%)\end{array} & \text { Ni/Co } \\ \begin{array}{l}\text { Average metallic phase of } \\ \text { hypersthene olivine chondrites (ref. 3) }\end{array} & 79.7 & 19.4 & 0.88 & 22.2 \\ \begin{array}{c}\text { Average metallic phase of bronzite- } \\ \text { olivine chondrites (ref. 3) }\end{array} & 88.0 & 11.4 & 0.55 & 20.6 \\ \begin{array}{c}\text { Average metallic phase of enstatite } \\ \text { chondrites* }\end{array} & 92.5 & 7.1 & 0.35 & 20.2 \\ \begin{array}{l}\text { Average metallic phase of pallasites } \\ \text { (ref. 3) }\end{array} & 88.4 & 11.0 & 0.55 & 20.0 \\ \begin{array}{c}\text { Metallic phase in Disko Island Basalt } \\ \text { (carbon free) (ref. 1) }\end{array} & 97 \cdot 6 & 1.76 & 0.68 & 2.6\end{array}$

* Average of flve superior analyses: Hvittis, Indarch, Saint Sauveur (ref. 4) and Abee (matrix), Abee (fragment) (ref. 5).
On the other hand, the metaliic masses occurring in the basic igneous rocks at Uifaq, Disko Island, West Greenland, have nickel and cobalt abundances and nickel/cobalt ratios almost indistinguishable from the metallic phase in the Macibini eucrite and very similar to that in the Binda howardite (Tables 1 and 2). The metallic masses in the Disko Island rocks are generally considered to have been formed by the virtually complete reduction of oxidized nickel and cobalt, and the partial reduction of oxidized iron, in a basic silicate magma as a result of reactions with carbonaceous matter derived from surrounding coal measures or carbonaceous shales which these rocks are observed to intrude ${ }^{1}$. In view of the close similarity between the metallic phase in the Disko Island basalts and the basic achondrites, it is suggested that the metallic phase in the basic achondrites has formed from partial reduction of the parent basic magmas from which these achondrites have evolved.

\section{J. F. LOVERING}

Department of Geophysics,

Australian National University, Canberra,

Australia.

${ }^{1}$ Lovering, J. F., Geochim. Cosmochim. Acta (in the press).

Lovering, J. F., Geochim. Cosmochim. Acta, 12, 238 (1957).

s Greenland, L. P., Ph.D. thesis, Australian National University, Canberra (1963) (unpublished).

- Wiik, H. B., Geochim. Cosmochim. Acta, 9, 279 (1956).

- Dawson, K. R., Maxwell, J. A., and Parsons, D. E., Geochim. Cosmochim. Acta, 21, $127(1960)$.

\section{PHYSICS}

\section{Chromium Oxide-Chromium Cermets}

THE preparation and properties of chromic oxidechromium cermets have been examined as part of a general investigation into the possibility of preparing metal-ceramic mixtures ('cermets') by partial reduction of refractory oxides. The method consists of pressing a mixture of chromic oxide and carbon, both in the finely divided state, into compacts and sintering to temperatures in the range $1,400^{\circ}-1,600^{\circ} \mathrm{C}$ in a vacuum of circa $10^{-4} \mathrm{~mm}$ mercury. The amount of carbon is calculated to give 1-10 per cent metallic chromium in the sintered body.

Under the foregoing conditions, considerable shrinkage of the compact occurs, resulting in an increase of density in a typical case from 3.2 to $4.7 \mathrm{~g} / \mathrm{cc}$. This can be compared with an increase in density from 3.2 to 3.4 for pure oxide sintered to the same temperatures. The increase in sintered density is accompanied by an increase in compressive strength from 3 tons/in. ${ }^{2}$ for the pure oxide to approximately 20 tons/in. ${ }^{2}$ for the cermets.

Provided that the temperature of sintering is sufficient to cause the reduction to proceed to completion, the most significant variable affecting sintered density is the proportion of carbon. Less than a threshold addition produces no effect, whereas more than the optimum causes the density and compressive strength to fall off, though less markedly. The latter deterioration is presumably due to an expansion effect of the carbon monoxide involved.

The mechanism responsible for this unusual shrinkage is being investigated.

This work is supported by special grant from the Department of Scientific and Industrial Research.

\section{H. E. N. Stone \\ N. A. Lockington}

High-Temperature Materials Section, Battersea College of Technology, London, S.W.11. 